\title{
Intersections between Modern and Contemporary Dance and Yoga Practice: A Critical Analysis of Spiritual Paths through Body Movement and Choreography
}

\author{
Aglaia Zafeiroudi \\ Department of Physical Education and Sport Science \\ University of Thessaly, Trikala, Greece
}

DOI: https://doi.org/10.36941/ajis-2021-0094

\begin{abstract}
Bodily movement, rhythmic response, physical exercise and related techniques are sources of spiritual awareness. Yoga and dance are both concerned with the relationship between spirituality and the physical body. This paper presents a literature review of yoga and modern and contemporary dance as spiritual bodily practices. An electronic literature search was undertaken using Scopus, Google Scholar, CINAHL, EMBASE, PubMed/MEDLINE and Web of Science databases to examine the integration of modern and contemporary dance with yoga practice. The review reveals a number of important choreographic and spiritual similarities between these practices, including coordinated movement of the body with the breath, sequences of movements, rhythm, gestures and energy management. Many modern and contemporary dancers, choreographers and artists, such as Graham, include yoga techniques in their choreography and teaching. Through bodily movements, yoga and dance allow for self-awareness and self-perception, which aid in connecting the body, the brain and the soul with the divine. The paper finally suggests and describes how a combination of these two practices may be applied in conjunction with rhythm and music to enhance spirituality through body movement. This paper sought to expand the ways in which movement through yoga and modern and contemporary dance can be considered and practiced in relation to spirituality.
\end{abstract}

Keywords: awareness, creativity, yoga, dance, body expression, breathing, mindfulness, choreography, spirituality, artistic leisure, creative recreation

\section{Introduction}

Yoga is thousands of years old and is widely practiced around the world. We have probably been dancing for at least as long as we have been human. Both dance and yoga use creative processes and rhythmic responses that manipulate the human body, mind and soul in space and time (Kumar, 2011). The harmony, bodily expressions, movements, alignments, breathing and rhythms of these practices inspire thought and perceptions of morality. Through yoga and dance, humans have found ways to improve the structure and function of their bodies, and to enhance their thinking, creativity and expression (Murcia, Kreutz, Clift, \& Bongard, 2010; Alpert, 2011; Butterfield, Schultz, Philippa, \& Proeve, 2017).

Dance and yoga have long been used as spiritual exercises (Margolin, 2014; Siddiqui, 2016). A variety of studies have demonstrated the significance of the two methods in allowing the individual to connect with the self and with the environment and its inhabitants (Kieft, 2014; Tompson et al., 
2018). Combining yoga and dance helps people to connect to their spiritual selves and allows for the realisation of the unique elements of these two diverse practices (Santillano, 2006). The philosophy, physicality and spiritual discipline of yoga are incorporated into the expression and creativity of dance and movement which, together, allow individuals to access their spiritual selves (Margolin, 2014).

The concept of spirituality has been explored in the context of leisure, sports and peak performance, including in music, nature, art, mediation and dance (Flower, 2016). Scholars have examined the therapeutic roles of yoga and dance in such areas as dancer injuries, eating disorders, fitness, stress and anxiety (West, Otte, Geher, Johnson, \& Mohr, 2004; Santillano, 2006). Pathways to spirituality have also been explored through specific dance styles, such as belly dance (Kraus, 2014), African dance (Monteiro \& Wall, 2011), ballet (Flower, 2016) and contemporary dance based on traditional Asian techniques (Khampha, 2015). However, such research is limited in the context of modern and contemporary dance.

This study sought to answer a number of broad questions. What is the ultimate purpose of practicing yoga and dance? Is this purpose related to physicality and the body? Does that purpose proceed to the function of the mind, the soul and spirit? Do yoga and dance provide experiences 'beyond the ordinary self' and everyday life?

This paper examines the integration of yoga into modern and contemporary dance and, through a critical and synthetic literature review, presents evidence of a number of important similarities between modern and contemporary dance and yoga as physical practices, and explores their relationship with spirituality through bodily movement and choreography.

\section{Research Methods}

An electronic literature search was undertaken using Scopus, Google Scholar, CINAHL, EMBASE, PubMed/MEDLINE and Web of Science databases for papers published between 2000 and 2020. The following search terms were used: 'yoga and/modern/contemporary dance and/or spirituality and/or body movement', 'yoga and creative dance and/or spirituality and/or performance and/or modern dance choreography'. The search was limited to papers written in English. Papers focusing on specific groups, such as pregnant women, children, and clinical patients, were excluded. The literature search included peer reviewed journal articles and books. Secondary references were selected from the bibliographies of the primary literature.

\section{Results}

\subsection{The meaning of spirituality}

Spirituality is a broad concept with many different meanings. The term has multiple definitions, reflecting the perceptions of those who define it (Ramaswamy \& Deslauriers, 2014). However, common to all of these definitions is the notion that spirituality transcends the physical and the material to focus on the spirit. 'Spirituality' comes from the Latin word spiritualitas, meaning to blow or breathe life into the soul (Victor \& Treschuk, 2020). Spirituality is a journey to the truth, a connection with something beyond ourselves and to something within ourselves. Certain interpretations of the concept focus on a sacred dimension. Lucchetti et al. (2015) postulate that spirituality incorporates supernatural beliefs and seeks to explain occurrences that go beyond known reality. Several scholars have attempted a more personal definition of spirituality as a quest to experience personal growth (Ivtzan, 2011).

Definitions of spirituality often overlap with those of religion, although several scholars have emphasized the differences between the two (Tanyi, 2002; Luccheti et al., 2015). Religion is described as a system of faith or worship which seeks to understand the world. It generally includes a transcendent being or beings and contains a meta-narrative (Milner, Crawford, Edgley, Hare-Duke, \& 
Slade, 2020). Taniy (2002) writes that religion usually involves rituals and practices and a higher power or 'God'. In some instances, spirituality has been defined as superior to religion, with religion are merely a subset of spirituality. In others, religion is given superiority and spirituality is viewed as a subset of religion (Gall, Malette \& Guirguis-Younger, 2011). However, according to most definitions, spirituality and religion are overlapping concepts that can easily be confused (Lucchetti et al., 2015). The boundary between spirituality and religion is narrow, and precisely defining them as separate entities is a daunting endeavour.

The current most common definition of spirituality postulates that it is anything that focuses on finding meaning in life (Zinnbauer et al., 1997). Spirituality is linked to many things. Each individual's conceptualisation of spirituality is unique and there is no right or wrong. For most people, spirituality is related to religion because their spiritual lives are intricately associated with religious institutions. People regularly attach their spirituality to institutions such as mosques, churches, synagogues and temples. Many formal religions use movement and rhythm as part of their practice such as swaying, bowing, kneeling, the walking rhythms of pilgrimage. Others attach their spirituality to activities that lead to personal growth and understanding. Spirituality through movement falls into this second group.

The definition of spirituality as the search to understand oneself easily incorporates such practices as exercise and movement. Brown (2013) argues that the relaxation arising from physical activity and movement is instrumental in helping people to discover themselves. A traditional view of spirituality as sitting in silent meditation or prayer (Stewart, 200o) limits other forms of selfrealisation that can help people connect with their inner selves. Prohibiting movement as a form of spirituality is detrimental, as some people use movement and exercise methods to connect with their inner selves.

For many people, spirituality and religion are not synonymous and spirituality has a broader and more personal definition, as it refers to the diverse and personal ways that people seek meaning, purpose, self-actualisation and connection with the inner self, other people and the universe. (Parsian and Dunning, 2009).

Religious and non-religious spiritual expression is essential to the health and wellbeing of many people, giving purpose, hope and meaning to their lives. Physicality is also related to health, quality of life and wellbeing (Kekäläinen, Freund, Sipilä, \& Kokko, 2020), although few studies have examined the link between spirituality and physical activity (Silfee, Haughton, Lemon, Lora, \& Rosal, 2017).

Physicality and spirituality are intimately interwoven concepts (Brown, 2013). The former involves activities that require physical movement. The deep emotional awareness that emanates from self-realisation when engaged in physical activity can help to develop spirituality (Miller, 2016). In addition, physical exercises and movements are sources of spiritual awareness.

Yoga and dance are both activities concerned with the physical aspects of the body, offering physiological, psychological, mental, emotional and aesthetic benefits (Murcia, Kreutz, Clift, \& Bongard, 2010; Williamson, 2016; Butterfield, Schultz, Philippa, \& Proeve, 2017). In addition, scholars have found that dance and yoga are experienced as spiritual practices that lead to wellbeing and health (Lifshitz, Nimrod \& Bachner, 2018).

\subsection{Modern and contemporary dance as spiritual practice}

Modern and contemporary dance are genres that combines many traditional styles (Manning \& Benson, 1986). The emergence of modern dance has been attributed to dissatisfaction with and revolt against the more formal ballet genre. It originated out of interactions between German and American performers, dancers, choreographers, schools and has evolved into a broad genre of dance. Contemporary dance developed through borrowing techniques and choreographies from a variety of dance styles (Kwan, 2017), including classical, modern and jazz, and it continues to evolve through borrowing from many different styles. Since both modern and contemporary dance have borrowed 
from similar dance styles, the two are viewed as closely related.

Modern and contemporary dance techniques are now dominant forms of dance in much of the world, and dancing has been shown to possess therapeutic qualities that serve as spiritual exercises (Bresnahan, 2015). Through dance, the individual can be possessed by the spiritual elements of dance. Dance also alleviates stress and pain by creating consciousness in the body. The awareness derived from dancing allows the individual to connect to the self and to develop awareness and understanding of the body (Tihanyi et al., 2016). For some, the transcendental aspects of dance have elements of the supernatural. A religious dimension can be achieved through the connection between the metaphysical and physical states of consciousness. Self-exploration and understanding can also be derived from dancing, leading to self-identification and the dancer's association with a particular culture.

Mastering the movements associated with dance leads to increased awareness of the body (Tantia, 2012). Taking charge of the body is realised through the execution of dance moves, leading to self-learning. Through dance, the individual can develop positive body image, self-confidence and positive self-perception. Self-perception is instrumental in shaping awareness and self-learning and it ultimately leads to well-being (Tihanyi et al., 2016). Therefore, the benefits to the spirit reaped from dancing are many, and spirituality can be derived from the movements associated with both contemporary and modern dance.

Dancing emerges at the confluence of internal and external factors that, together, bring about bodily movement. Ramaswamy and Deslauriers (2014) postulate that dancers, dance styles and the dancing experience coexist in a spiritual space. Oneness can be realised through a resonant experience that links the dancer and the audience. Dance as spirituality leads to self-acceptance of how one is, rather than how one should be. Partnering others in dance is an example of learning to trust others, to let go and to discover life from new dimensions (Fraleigh, 2012). Dancing also creates authenticity and leads to self-awareness and physical well-being. The joy and satisfaction derived from dancing can lead to a sense of prosperity. Each of these outcomes can be considered to have spiritual overtones. The fledgling skills of the dancer create a sense of renewal and increased vitality on the part of the dancer and the audience.

Dancing creates an awareness that allows dancers to discover both themselves and their partners (Fraleigh, 2012). Dancing in groups necessitates a sense of awareness of each member of the group towards everyone else in the group. The touch and movement of dance allows for learning about the self and about one's dance partner or dance group. Awareness of the self and of others connects to spirituality through the process of self-learning. Connection between dancers depends on communication (Fraleigh, 2012). Modern and contemporary dance enables human beings to connect to their spirituality.

Dance of awareness (DoA) is a form of dance that connects movement with awareness by recognizing that individuals and those around them form the backbone on which human experiences are built (Osbond \& Brown, 2016). Movement through dance increases self-awareness, ultimately leading to self-acceptance and appreciation of those around us. Dancing allows individuals to achieve physical, mental, emotional and spiritual well-being (Osbond \& Brown, 2016). DoA provides the ability to re-experience and rediscover the self, leading to development. Payne et al. (2016) suggest that dance movement is a form of psychotherapy that allows the individual to connect with the self. Therefore, dancing promotes connections with the individual's spiritual side.

Music, and the dancing with which it is associated, evokes bodily responses and helps to connect our bodies to our spiritual selves (Hanna, 1995). Foremost, the senses are heightened as the body pays attention to the physical movements derived from dancing. The dancer develops awareness by focusing on the connection between the body and its surroundings, including the ground beneath. In addition, expressing oneself through dance provides a significant connection to spirituality. Dancing releases energy, which further allows for a connection to spirituality. The movements associated with dance also enable a deeper connection with the self and with those individuals in the dancer's immediate environment. These phases lead to the discovery of the inner 
self, providing a true reflection of who we are. Barton (2011) postulates that discovering one's true nature, free from environmental influences, is integral to self-awareness, which is the backbone of spirituality.

Dancing is beneficial to the body, the mind and spirituality (Margolin, 2014). The value of dancing as a method of self-expression cannot be overemphasized. In addition, dancing encourages ingenuity and creativity, as well as creating social awareness and connections with others. Social awareness allows for understanding of others, which is critical to ensuring self-understanding. Moreover, dance and movement are significant therapeutic forms that help to develop selfrealisation. Margolin (2014) postulates that dance is an integral spiritual exercise, as it helps us to know who we are and how we are different from others.

\subsection{Yoga and spirituality}

Yoga has become a popular form of physical fitness training in the West (Feuerstein, 2003). However, yoga practice runs much deeper than this. Collins (1998) and Feuerstein (2003) argue that yoga is not only a means of acquiring physical fitness, as consistent practice transcends health benefits alone. Yoga for physical fitness, therefore, offers a pathway to the discovery of more profound meaning.

Originating in India, yoga is concerned with more than fitness or the physical techniques that we associate with hatha yoga. Even in India, the term 'yoga' defies definition (Joshi, 1965), and it has been associated with supernatural and religious beliefs. However, Mukherjee (2016) defines yoga as a group of practices involving the physical, mental and spiritual aspects of human beings. It allows for the connection of the individual to the transcendental self. Yoga is often associated with meditation and as mentioned above, an exercise practice for physical fitness. Yoga also has many spiritual benefits.

As a spiritual exercise, yoga enables greater connection between individuals and between the individual and their environment (Hanna, 1995). Yoga practice also enables connection to the self, building on the yogic philosophy that our problems are associated with a separation from our true selves. Separating oneself and those in the immediate environment, including non-human aspects of that environment, is also seen to be at the root of human problems. Not accepting one's true self lead to confusion and causes problems. Ignorance of one's own nature is a significant contributor to life's problems. Yoga also creates an awareness that many of the problems one faces are due to false identification of one's experiences and relationships with others.

There are eight limbs to yoga that intersect to increase awareness (Jeuland Ware, 2007). Yamas and niyamas guide personal reflection (Lacasse, Santarossa, \& Woodruff, 2019), which aids in selfawareness and self-discovery. Asanas are the poses, physical exercises or choreographic flow of movements that cultivate awareness and concentration and train the mind. The spiritual purpose of asanas is the attainment of the eighth limb samadhi, the state of meditative consciousness. According to the first century Yoga Sutras, compiled by Patanjali, and the fifteenth century text Hatha Yoga Pradipika, by Yogi Svatmarama, asanas include spiritual goals that involve tantric manipulation of the subtle body. Practicing asanas creates an awareness of being part of all of creation and of the universal spirit. This is why the asanas are named after plants, animals, birds and legendary heroes. At a more physical level, they increase strength, endurance, vitality, flexibility, balance and detoxification.

Asana, pranayama and dharana enhance awareness of all aspects of the human being, enabling an understanding of one's connections to others and to the environment (Lacasse et al., 2019). Awareness is built in the mind, body, breath and soul. Focus is nurtured, leading to an understanding of the self and the expulsion of problems that arise from not focusing on oneself and one's surroundings. Pratyahara, dharana and dhyana are the limbs that bring about focus (Lacasse et al., 2019).

Yoga frames its goals around the relationship between consciousness (purusha) and materiality (prakriti). It teaches practitioners to be present in and to connect with the immediate environment, 
thus alleviating the problems associated with separation from that environment. The use of body movements and gestures (mudras) enhances focus and affects the body's energy (Carroll \& Carroll, 2012). Furthermore, yoga includes the chanting of mantras, which are groups of melodic words or phrases. These are often repeated alongside sequences of poses or during meditation. This rhythmic or repetitive activity has a powerful effect on the brain, leading to improved awareness and concentration in the present moment (Lolla, 2018).

According to yoga philosophy, habits, both positive or negative, develop over time. Yoga enables behavioural change that allows the individual to live well with others. Self-acceptance and the ability to cope with basic human emotions, such as anger and tension, are developed through yoga (Barton, 2011). Cognitive change can also be achieved through yoga's therapeutic practices. Yoga is a philosophy and practice of connection through which an individual comes to understand internal connections, including how the various aspects of the body are connected, and understanding the self, others and the environment.

\section{Discussion}

The integration of modern and contemporary dance, yoga and spirituality.

It would seem that yoga and modern and contemporary dance are not merely practices. In the reviewed literature, they have also been described as forms of participation and ceremony, and as ways of life and existence. Both yoga and dance have long been associated with religion, magic, love, birth, death and nature (Tsilimigra, 1993; Hartranft, 2003).

According to the philosopher Roger Garaudy (1980), the word 'dance' ('danza', 'tanz', etc.), in all European languages comes from the root 'tan', the Sanskrit word for 'trend'. Dance refers to the intense feeling and expression of the relationship between humans and nature, society, the future, the gods and the universe. Through dance, humans attempt to create an active relationship between themselves and nature, and to participate in and synchronise with the movement of the universe, and to understand and transcend its powers.

The original yoga texts were written in Sanskrit and the word 'yoga' is derived from the Sanskrit root 'yuj', meaning 'to join', 'to yoke' or 'to unite'. Yoga practice leads to the union of individual consciousness with universal consciousness, indicating a perfect harmony between mind and body, human and nature (Hartranft, 2003). Hindu philosophy describes yoga and dance as two rivers stemming from the same source through the dance of the god Shiva. Kieft (2014) writes that, through sequential movement, dance enables participants to get in touch with other states of consciousness, and to participate in all of existence, leading to different dimensions.

Dancers spontaneously create movement when they engage in improvised dance. The development of movement is facilitated through a variety of creative explorations, including body mapping through levels, shapes and dynamics. Dance improvisation is an exploration between the known and unknown, between gentle and strong, swing and sway, sharp and continuous, straight and curved, release and contraction. The participant must decide on a combination of these principles. This awakens emotional and spiritual intelligence that enhances different states of conscious (Snowber, 2012).

Expression using the hands and other parts of the body is a common element of modern and contemporary dance and yoga. Gestures or mudras form part of the artistic language that contributes to deeper self-expression and creative unfolding. Such bodily movements project attitudes and emotions and are used in yoga and more theatrical forms of dance, such as modern dance. In yoga, mudras, gestures and movements are combined with breathing and pranayama to activate the energy of the body and improve the quality of the movement (Carroll \& Carroll, 2014). In modern and contemporary dance, the breath provokes contrasts, and creates dynamics such as swing and sway, tension and relaxation, jazz and lyrical qualities. Gestures and movements create greater bodily and environmental awareness, enhance expression and awaken spirituality (Margolin, 2014; Ramaswamy \& Deslauriers, 2014).

In Hinduism, the Yoga Sutras are associated with the rhythmic sound at the genesis of the 
world. This sound is described as the root of all creation and is expressed primarily by the sound and mantra "om". Kumar (2011) refers to mantras as measuring units for the division of time. Many mantras have tone, melody and rhythm, and are also commonly used in western yoga. Mantras affect autonomic cardiovascular rhythms and enhance the force of movements, and increase levels of energy, concentration and awareness (Bernardi, Bandinelli, Cencetti, Fattorini, Wdowczyc-Szulc, Lagi, 2001; Kumar, 2015; Lolla, 2018).

In modern and contemporary dance, rhythm is a primary element created through music, song, poetry and drama. Rhythm is experienced through bodily movement and action. Isolations, kicks, leaps, angles, contractions, curves, inverted hands, oppositions, parallels, coordinated arm lines and other gestures are used according to rhythm. Movement emanates from within the body, touching deep human emotions, provoking expression, thinking, awareness and bringing joy, happiness, meaning and spirituality (Huxley, \& Burt, 2014; Greenhead \& Habron, 2015; Kieft, 2014.

Perhaps the greatest similarity between yoga and modern and contemporary dance is the use of the breath (Green, 2002). Breathing animates and moves the body. Physical exercise, asanas and choreography all rely on the breath. Breathing revitalises the body, steadies the emotions and gives dynamism and quality to the practice of movement (Green, 2002). Yoga and dance also share the concentration, symmetry and alignment of the body during poses, gestures and movements.

As practices, yoga and dance use the body for physical exercise and asanas. These physical exercises contain specific alignments and techniques. Both yoga and dance require thinking when learning a new asana or dance step. But the flow of the movement comes when the participant 'stops' thinking, and the movement is in the body (Green, 2002). This fact promotes self-concentration and quiets the mind, which are the first steps to self-awareness (Snowber, 2012). The alignments and techniques used in yoga and modern and contemporary dance connect body, mind, soul, heart, imagination and creative thinking. Margolin (2014) writes that "creative movement encourages inner impulses to take form. The conscious mind lets go of direction while it observes. It cooperates and allows the unconscious mind - deep feelings - to express themselves unjudged or scrutinised." Furthermore, yoga asanas and dances are performed mostly barefoot. Bare feet grip the surface better and help with balance and traction. Being barefoot helps one to feel more connected to the earth and to one's emotions and instincts. This sense of groundedness enhances the union with the rest of the world - humans, animals and plants - and stability improves thinking, awareness and inspiration (Sandler \& Lee, 2013; Strauss, \& Mandelbaum, 2013; De Tord \& Brauninger, 2015).

Aubrecht (2017) examined one aspect of the relationship between modern and contemporary dance and yoga practice that seems to have been forgotten. He wrote that the great dancers and choreographers practice yoga and use breathing techniques and poses in their pedagogy and choreography. These artists are inspired by a variety of yoga forms, including raja, bhakti and hatha yoga. The great American modern dancer Ruth St. Denis integrated yogic ideas to promote spirituality in her international modern dance performances. Modern dancer and choreographer Martha Graham adapted yogic asanas, and spiritual and breathing techniques for her dance practice, many of which are still performed today. Meanwhile, Merce Cunningham used yoga asanas to render his art elite, special, more spiritual and distinct.

The incorporation of yoga into contemporary and modern dance brings therapeutic benefits, such as healing and connection to the spiritual dimensions of life. In yogic philosophy, the body and the mind are understood to exist as one (Bajaj \& Vohra, 2011). Therefore, an imbalance in either leads to problems in the other. Yoga and dance create self-awareness and self-perception, thus connecting the body and the brain. Self-awareness through yoga and dance allows for the quick circulation of information within the individual. Knowing oneself bestows power, which contributes to the alleviation of most human problems.

Yoga and dance have been found to possess therapeutic properties that aid in relieving stress, thus contributing to disease prevention and treatment (Brauninger, 2012; Li, Goldsmith \& Goldsmith, 2012). Many widespread chronic diseases are aggravated by stress, and stress management is now a vital element of disease management (West et al., 2004). Barton (2011) found that a blend of yoga and 
dance reduced stress levels in research participants. Reduction in stress can be attributed to the nurturing of self-awareness through the practice of yoga and dance. Despite the different movements involved in yoga and dance, both have therapeutic elements vital to stress relief (West et al., 2004). The incorporation of yoga and dance ensures that practitioners reap the benefits of both techniques.

Bräuninger (2012) explored the use of yoga and dance and movement therapy in relieving stress and highlighted the significance of treatments in stress reduction. These therapies led to selfrealisation and connection to the inner body. Self-awareness helps to alleviate a variety of problems that arise from not accepting oneself and one's surroundings. Meanwhile, Barton (2011) indicated that yoga and dance movement therapy predispose research participants to coping mechanisms that aid in mitigating stressful situations. However, it should be noted that the use of self-reporting may have reduced the efficacy of the study.

For a long time, movement and dance therapists have sought to incorporate other movement disciplines into their therapy, including martial arts and yoga. Among the martial arts that have been incorporated into dance and movement therapy are tai chi, karate and qi-gong (Yeung, Campbell, \& Chan, 2019). These techniques increase the efficacy of dance and movement practices. Philosophical and spiritual concepts from Zen and other forms of Buddhism have also been incorporated into dance and movement therapy (Margolin, 2014), and mindfulness has gained acceptance as a way to integrate philosophical and spiritual concepts into dance and movement.

Life-limiting diseases are of particular concern in the contemporary word. These diseases require special attention and care beyond the use of clinical methods. Treatments for some lifelimiting diseases include yoga and dance therapy. Aktas and Ogce (2005) conducted a study of the use of yoga and dance therapies among cancer patients and provided significant insight into the role of these therapies in alleviating problems among patients. These problems were generally found to be physical rather than psychological and emotional.

Research points to the benefits of incorporating yoga into modern and contemporary dance. The incorporation of yogic practices into dance has led to the realisation of many health and wellbeing benefits. Yoga is also used to improve the creativity of contemporary and modern dance choreographers and directors and to improve dancer fitness and alleviate the risk of injury. However, more can still be done to enhance physicality and spirituality through the practice of yoga.

Mattocks (2014) found that yogic practice aids dancers and, in particular, pre-professional dancers in training. The incorporation of cross-training into dance supports dancers in keeping fit, allowing for proper movement and reducing the risk of injury to both dancers and their partners. A variety of cross-training techniques have been infused into dance practice. From one hand, yoga is a physical practice, making it the most common cross-training practice used by dancers. Proper crosstraining leads to maximum fitness and translates into improved dance abilities. However, yoga can also be incorporated into dance and movement in ways that transcend fitness. Incorporating yogic practices into choreography and movement sequencing can be instrumental in helping dancers to experience their spiritual side.

Yoga has a number of significant benefits for contemporary dancers. Dance, and especially contemporary dance, requires a lot of physicality and stamina. Many professional dancers must simultaneously wear several hats, as choreographers, producers, and fundraisers. The many facets of a dancer's life require a great deal of sacrifice, including ensuring proper dance movements and coordination. Yoga provides dancers with continuity throughout their lives and improves the fluidity of their movements. Practicing yoga gives peace of mind, which is a significant factor in replenishing and nourishing the body and enabling the body to be used as a means of expression (Barbour, 2014). Yoga also helps dancers to develop discipline and create space, and to focus on specific aspects of the physical body, such as the breath.

One important difference between yoga and modern and contemporary dance is that the former focuses on the mind and rejects competition, perfection and putting pressure on the body to perform. Professional dance, on the other hand, focuses on performance and competition, causing stress, anxiety and pressure, which lead to psychological and emotional disorders, such as lack of focus, in 
addition to physical injury.

Yoga also assists dancers when recovering from injury (Nordin-Bates et al., 2011). The healing effects of yoga enable the dancer to connect the physical and spiritual elements of the body. Injuries are a common problem for dancers, occurring in many parts of the body, but especially the muscles, hips, arms and legs. Simpson (2006) found that up to $90 \%$ of the injuries experienced by dancers are the result of fatigue. Therapeutic yoga and dance mitigate the risks posed by fatigue. The combination of yoga and dance movements has been found to provide a method of connecting to the body's physicality (Aubrecht, 2017), thus reducing the chances of injury and allowing the dancer to function optimally. Engaging in conditioning activities reduces the risk of injury, and yoga, in addition to other activities, such as swimming, aerobics and gym work, have been found to be vital conditioning activities (Wiese, Keil, Rasmussen, Olesen, 2019).

Globalisation has led to worldwide cultural exchange and the spread of yoga into Western culture. As a result, yoga and contemporary dance techniques have become integrated. The use of yoga and dance as modern therapies has gained traction in recent years (Aktas \& Ogce, 2005). Yoga therapy helps to alleviate problems associated with stress and lack of self-awareness and ensures more healing. Yoga's Indian origins and its incorporation into Western dance techniques has led to improved choreography, allowing for better sequencing of movements and, through the increased self-awareness of dancers, producers and choreographers, improved dance expression.

The development of yoga in contemporary dance choreography and performance has improved the wellbeing to all those involved in the integration process (Aubrecht, 2017). Yoga is a method that embodies knowing and helps to develop integrity. Yoga practice also realises awareness of the body and the emotions (Dittmann \& Freedman, 2009). The expression of feelings is a spiritual exercise accomplished by the incorporation of yoga into dancing movement. Performances that blend yoga and contemporary dance have healing and restorative effects for all involved (Aubrecht, 2017). The creative process required to incorporate yoga into modern dance allows for detachment from the everyday world to tap into the self. This helps to ground the human experience in attention to the self and connection to the world and the whole universe.

One significant aspect of yoga is that it incorporates a broad range of genres associated with traditional exercise. Bharatanatyam and iyengar yoga have been incorporated into contemporary dance choreography and practice (Vaughan, 2014). These forms of yoga allow for improvements in kinaesthetic awareness of the dance and the choreography. Yoga allows for the creation and adoption of multiple perspectives related to the body and the mind. These perspectives include the gestural, accented, spiritual, energetic, reflective, environmental and ecological body. The movements of yoga and contemporary dance have been used as spiritual exercises that have led human beings, and especially those who dance, to self-awareness.

Yoga and asana practices have also been incorporated into modern dance (Miller, 2015). Many aspects of yoga have found their way to the United States and been used by dance communities. In addition to their integration into dance, the posture exercises of yoga practice are used by dance communities, and yoga is an inspiration for choreographic creativity. Yoga helps to ensure understanding between the mind and the body, and it improves non-linear thinking, which helps to improve creativity, leading to enhanced dance techniques (Miller, 2015). Breathing and meditation are forms of yogic practice that encourage non-linear thinking. Mattocks (2014) postulates that yoga has been incorporated into a variety of modern dance techniques because of the benefits it brings to choreography and sequencing movements through the expression of feelings.

Yoga is used in extemporaneous dance to encourage improved sequencing of movement and choreography (Oliveira, 2016). The incorporation of yoga is to be found in the creative process and in the use of gesture to express thoughts and feelings. The body, the mind and the breath are all incorporated into the creation of a dance. It is essential that the choreographer and dancer are aware of the body and the movements it makes. Consciousness and respect for the body and its movement are made possible by the self-awareness derived from yoga. These are essential for the development and performance of extemporaneous dance. The coordination of bodily movement and the breath are 
fundamental to extemporaneous dance, which has been described as a moving meditation (Fraleigh, 2012). The infusion of yoga into dance allows for improved choreography and movement sequencing.

The origins of yoga can be traced to India and there is widespread incorporation of yogic practice into many aspects of cultural life in that country. Many Indian dance styles, for example, is inextricably entwined with yoga, with gestures, postures and movements drawn from yoga (Gupta, 200o). The infusion of yoga into dances allows for concentration which translates into improved sequencing and movement. Based on the literature yoga also aids choreographic creativity.

Several Australian-based dance companies offer contemporary dance that combines ballet and modern techniques (Roche \& Huddy, 2015). In recent years, a desire for increased fitness has led to the introduction of fitness classes into modern dance practice. These classes include boxing, yoga, Pilates and cardiovascular training. Although these fitness classes deviate from the norm, their significance cannot be denied, as they ensure that dancers have the strength required of contemporary dance. As a fitness method, yoga also helps dancers to prepare for the daily demands of creativity. Yoga has been incorporated into modern dance to aid creativity, and to provide for better movement sequencing and choreography. In the context of Australian contemporary dance, yoga is the most commonly used fitness method, owing to its benefits to the process of creativity.

Perception and action determine how a dancer interprets instructions. Cazemajou (2013) conducted research with amateur adult pupils who use yoga to prepare for their contemporary dance classes. A variety of forms of yoga can be used for rehearsal, depending on the preferences of the pupils. In this case, the pupils chose to practice iyengar yoga. Yoga acts as a trigger and determines how the body experiences the sensations that arise from the instructions given by the teacher or choreographer.

In general, yoga and dance play a role in life. Feuerstein (2003) describes prana as the manifestation of the life force in the external environment. Yoga directs the breath, allowing the life force to circulate from within the individual to the outside world (Sengupta, 2012). In the absence of yogic practice, breathing is obstructed, making it impossible to experience the life force. Feuerstein (2003) postulates that a lack of proper breathing control is detrimental as it impedes the circulation of the life force. Correct breathing control realised through yogic practice allows the life force to circulate freely in the body, thus improving life.

The psycho-spiritual potential of the body can only be realised through the proper circulation of prana from within the body to the outside. Regulation of the breath is a specific form of yoga known as pranayama, which seeks to improve health through boosting the immune system, improving digestion, alleviating and mitigating disease, reducing stress levels and improving sleep (Saoji, Raghavendra, \& Manjunath, 2017). According to yoga philosophy, conscious dying has also been attributed to the control of prana. Saoji et al. (2017) posit that immense bliss can be obtained through pranayama by ensuring that life energy circulates to all parts of the body.

According to Lawrence (2012), intuitive knowledge is perception of the world through consciousness. Yoga and dance practice can be used to develop awareness and intuition. Consciousness can only be realised through the connection of the body, the mind and one's actions. Yoga and contemporary or modern dance help to make connections to the spiritual domain through physicality, a phenomenon that allows practitioners to improve their intuition and consciousness. Understanding oneself is the best way to improve one's intuition and consciousness.

Yogic practices can be incorporated into a variety of choreographed dance styles, rather than simply being used during warm-up and as part of fitness regimes. The range of yoga techniques in existence means that yoga can easily be incorporated into different dance styles. Choreographing movements borrowed from different yoga styles would allow for the greater use of yoga in dance.

Standing, balancing asanas can be used alongside tendus, weight transferences, travelling and other dance movements, such as drifting, jazz or lyrical dynamics. Sitting and acrobatic asanas can be combined with dance floor exercises, such as side ripples and falls, creating different dynamics and contrasts. Conscious breathing, mudras, dance techniques and chakra activations through asanas can be used as preparatory tools for improvisation. Surya namaskars (sun salutations) and other vinyasas 
can be enriched with isolations, such as arm swings and circles, or be combined with splits, jumps, bounces and turns. Forward, upward, backward and side stretches can be expanded by combining them with yogic asanas such as warrior, cobra, triangle and camel poses. Breath and release dance exercises can be enhanced with deep breathing yogic and relaxation techniques.

Furthermore, dance balances can adapt dristhis (focused gaze yogic practices) to improve stability and awareness. The use of mantras and mudras can redirect and strengthen the body's energy. Imagery and visualisation also can assist the memory, and the quality and alignment of dance techniques. Yogic philosophy can bring awareness, concentration and spirituality to the dancer, bringing different ethics, values and dimensions to the physical body that go beyond merely performing the steps. Combining yoga with dance movements becomes a creative spiritual choreography that can be performed to music or mantra rhythms using different directions and patterns in space.

Integrated yoga and dance principles can help participants to deepen their knowledge of movement, anatomy and musicality, as well as expanding their motor and mental skills. Choreographers, producers and dancers who possess knowledge of both yoga and dance routines allows for the infusion of yogic practice into dance styles and moves. Allowing dancers to experience yogic practice also helps to ensure better expression of feelings and emotions, which ultimately translates into the improved use of yoga in dance.

Yoga has recently gained traction in a variety of sectors, including in schools, where it has multiple applications (Otto, 2014). Beliefs about yoga have changed to the extent that yoga and dance are now commonly practiced in schools. Otto (2014) points out that a growing awareness of the need for strength and flexibility training in children, teenagers and young adults has led to the acceptance of yoga and dance in schools. Yoga and dance also contribute to stress and anxiety management, and are, therefore, increasingly incorporated into school curricula in the West.

In recent decades, there has been increasing interest in the combination of modern dance and yoga (Miller, 2015). The many potential benefits of contemporary dance and yoga have been the focus of much research. Modern dance and yoga are used in several contexts to enable practitioners to achieve spiritual control, including in healthcare, education and leisure. Modern and contemporary dance are enhanced by the symmetry, dynamics, qualities and the aesthetics of yoga practice. Yoga improves movement sequencing and choreography in a variety of dance forms. Yoga significantly contributes to the realisation of self-awareness, thus allowing for the expression of emotion. It, therefore, contributes to more expressive and improved dance. Understanding human emotions is crucial to improving their expression.

The great dancers and choreographers sought to incorporate yoga into modern and contemporary dance to create artistic magic that endured on the stage and will go down in dance history. They sought to frame and strengthen the reasons why they practiced dance, to capture their emotions while dancing and to transmit those emotions from the stage to the audience. These feelings go beyond steps, technique, timing and space.

\section{Conclusion}

This paper sought to expand the ways in which movement through yoga and modern and contemporary dance can be considered and practiced in relation to spirituality. Both practices enable participants to live unique experiences with enhanced spirituality, contributing to an improved overall sense of wellbeing. The most significant value of this paper is that it invites participants into a different relationship with bodily movement, to see beyond steps, alignments, techniques and the self. Further empirical research is required in different national contexts, to explore the values that shape spirituality and whether spiritual experiences of yoga practice are universal. In addition, an exploration of different choreographic methodologies that promote the integration of yoga and dance practice to promote wellbeing should be conducted. 


\section{References}

Aubrecht, J. F. (2017). Choreographers and Yogis: Untwisting the Politics of Appropriation and Representation in U.S. Concert Dance. Doctor of Philosophy dissertation, University of California, Riverside.

Aktas, G., \& Ogce, F. (2005). Dance as a therapy for cancer prevention. Asian Pacific Journal of Cancer Prevention, 6(3), 408. [Online] Available: https://www.researchgate.net/profile/Filiz_Ogce/publication /7530516_Dance_as_a_Therapy_for_Cancer_Prevention/links/53f50290ocf22beo1c3for65/Dance-as-aTherapy-for-Cancer-Prevention.pdf (November 12, 2020)

Alpert, P. (2011). The health benefits of dance. Home health care management \& practice, 23(2), 155-157. https://doi.org/10.1177/1084822310384689

Bajaj, T., \& Vohra, S. S. (2011). Therapeutic implications of dance. Amity Journal of Applied Psychology, 2(1).

Barbour, K. N. (2014). Searching for bliss: Insights and challenges in yoga and contemporary dance choreography. Dance Research Aotearoa, 2, 79-10o. https://doi.org/10.15663/dra.v2i1.29

Barton, E. J. (2011). Movement and mindfulness: A formative evaluation of a dance/movement and yoga therapy program with participants experiencing severe mental illness. American Journal of Dance Therapy, 33(2), 157-181. https://doi.org/10.1007/s10465-011-9121-7

Bernardi, L., Bandinelli, G., Cencetti, S., Fattorini, L., Wdowczyc-Szulc, J., \& Lagi, A. (2001). Effect of rosary prayer and yoga mantras on autonomic cardiovascular rhythms: Comparative study. BMJ, 323, 1446. https://doi.org/10.1136/bmj.323.7327.1446

Bräuninger, I. (2012). Dance movement therapy group intervention in stress treatment: A randomized controlled trial (RCT). The Arts in Psychotherapy, 39(5), 443-45o. https://doi.org/10.1016/j.aip.2012.07.002

Bresnahan, A. (2015). The Philosophy of Dance. [Online] Available: https://stanford.library.sydney.edu.au /archives/spr2015/entries/dance/ (October 16, 2020)

Brown, D. H. K. (2013). Seeking spirituality through physicality in schools: Learning from 'eastern movement forms'. International Journal of Children's Spirituality, 18(1), 30-45. https://doi.org/10.1080/1364436X.2013.776521

Butterfield, N., Schultz, T., Rasmussen, P., \& Proeve, M. (2017). Yoga and mindfulness for anxiety and depression and the role of mental health professionals: A literature review. The Journal of Mental Health Training Education and Practice, 12(1), 44-54. https://doi.org/10.1108/JMHTEP-01-2016-0oo2

Carroll, C, \& Carrol, R. (2012). Mudras of India. Singing dragon, UK.

Cazemajou, A. (2013). The instructions as triggers for action and perception in a yoga/contemporary dance class. Staps: Revue Internationale des Sciences du Sport et de l'Éducation Physique, 34(102 2013/4), 61-74.

Collins, C. (1998). Yoga: Intuition, preventive medicine, and treatment. Journal of Obstetric, Gynecologic, \& Neonatal Nursing, 27(5), 563-568. https://doi.org/10.1111/j.1552-6909.1998.tbo2623.x

De Tord, P. \& Brauninger, I. (2015). Grounding: Theoretical application and practice in dance movement therapy. The Arts in Psychotherapy, 43, 16-22. https://doi.org/10.1016/j.aip.2015.02.001

Dittmann, K. A., \& Freedman, M. (2009). Body awareness, eating attitudes, and spiritual beliefs of women practicing yoga. Eating Disorders, 17(4), 273-292. https://doi.org/10.1080/10640260902991111

Feuerstein, G. (2003). The Deeper Dimension of Yoga: Theory and Practice: Shambhala Publications.

Flower, L. (2016). "My day-to-day person wasn't there; it was like another me": A qualitative study of spiritual experiences during peak performance in ballet dance. Performance Enhancement \& Health, 4, 67-75. https://doi.org/10.1016/j.peh.2015.10.003

Fraleigh, S. H. (2012). The ways we communicate: Somatic dance and meditation as a bridge. Somatics. [Online] Available: https://digitalcommons.brockport.edu/cgi/viewcontent.cgi?article=1004\&context=dns_facpub (December 2, 2020)

Garaudy, R. (1980). Dance in life. Iridanos Publishing, Athens. Translation from Tsoutsoura M.

Gall, T. L., Malette, J. \& Guirguis-Younger, M. (2011). Spirituality and Religiousness: A Diversity of Definitions, Journal of Spirituality in Mental Health, 13(3), 158-181, https://doi.org/10.108o/19349637.2011.593404

Green, J. (2002). Somatic Knowledge: The Body as Content and Methodology in Dance Education, Journal of Dance Education, 2(4), 114-118. https://doi.org/10.1080/15290824.2002.10387219

Greenhead, K. \& Habron, J. (2015). The touch of sound: Dalcroze Eurhythmics as a somatic practice. Journal of Dance \& Somatic Practices, 7 (1), 93-112. https://doi.org/10.1386/jdsp.7.1.93_1

Gupta, R. K. (2000). A Yoga of Indian Classical Dance: The Yogini's Mirror. Simon and Schuster.

Hanna, J. L. (1995). The power of dance: Health and healing. The Journal of Alternative and Complementary Medicine, 1(4), 323-331. https://doi.org/10.1089/acm.1995.1.323

Hartranft, C. (2003). The Yoga-Sutra of Patanjali: A New Translation with Commentary. Shambhala, Boston. 
Huxley, M. \& Burt, R. (2014). Concerning the spiritual in early modern dance: Émile Jaques-Dalcroze and Wassily Kandinsky advancing side by side. Dance, Movement \& Spiritualities, 1(2), 251-269. https://doi.org/10.1386/dmas.1.2.251_1

Intzan, I., Cha, C., Gardner, H., \& Prashar, K. (2011). Linking Religion and Spirituality with Psychological Wellbeing: Examining Self-actualisation, Meaning in Life, and Personal Growth Initiative, Journal of religion and health, 52, 915-929. https://doi.org/10.1007/s10943-011-9540-2

Jeuland Ware, C. (2007). Yoga and psychotherapy. Yoga Therapy Today, 3(2), 15-17.

Joshi, K. (1965). On the meaning of yoga. Philosophy East and West, 15(1), 53-64.

Kekäläinen, T., Freund, A. M., Sipilä, S., \& Kokko, K. (2020). Cross-sectional and longitudinal associations between leisure time physical activity, mental well-being and subjective health in middle adulthood. Applied Research in Quality of Life, 15, 1099-1116. https://doi.org/10.1007/s11482-019-09721-4

Kieft, E. (2014) Dance as a moving spirituality: A case study of movement medicine. Dance, Movement \& Spiritualities, 1(1), 21-41. http://dx.doi.org/10.1386/dmas.1.1.21_1

Khampha, R. (2015). Creating a contemporary dance based on traditional techniques and

spirituality - fusing elements from Lanna (Thailand), Indonesia and Japan. Journal of Urban Culture Research, 11, 76-79.

Kraus, R. (2014). Transforming spirituality in artistic leisure: How the spiritual meaning of belly dance changes over time. Journal for the Scientific Study of Religion, 53(3), 459-478.

Kumar, R. (2011). Essays on Indian music. Discovery publications, UK.

Kumar, R. (2015). Vedic mantras: An influential factor for spiritual health. International Journal of Science and Consciousness, 1(2), 9-14.

Kwan, S. (2017). When is contemporary dance? Dance Research Journal, 49(3), 38-52.

Lacasse, J., Santarossa, S., \& Woodruff, S. J. (2019). Yoga on instagram: Understanding the nature of yoga in the online conversation and community. International Journal of Yoga, 12(2), 153. https://doi.org/10.4103/ijoy.IJOY_50_18

Lawrence, R. L. (2012). Intuitive knowing and embodied consciousness. New Directions for Adult and Continuing Education, 134, 5-13.

Li, A. W., Goldsmith, P. D., \& Carroll-Ann W. Goldsmith, C. W. (2012). The effects of yoga on anxiety and stress, Alternative Medicine Review, 17(1), 21-35.

Lifshitz, R., Nimrod, G., \& Bachner, Y. G. (2019) Spirituality and wellbeing in later life: a multidimensional approach, Aging \& Mental Health, 23(8), 984-991. https://doi.org/10.108o/13607863.2018.1460743

Lolla, A. (2018). Mantras help the general psychological well-being of college students: A pilot study. Journal of Religion and Health, 57, 110-119. https://doi.org/10.1007/s10943-017-0371-7

Lucchetti, G., Koenig, H. G., Pinsky, I., Laranjeira, R., \& Vallada, H. (2015). Spirituality or religiosity: Is there any difference? Brazilian Journal of Psychiatry, 37(1), 83-83. https://doi.org/10.1590/1516-4446-2014-3610

Manning, S. A., \& Benson, M. (1986). Interrupted continuities: Modern dance in Germany. The Drama Review: TDR, 30(2), 30-45. https://doi.org/10.2307/1145725

Margolin, I. (2014). Bodyself: Linking dance and spirituality. Dance, Movement \& Spiritualities, 1(1), $143-162$. https://doi.org/10.1386/dmas.1.1.143_1

Mattocks, N. A. (2014). Yoga And dance: Effects of yogic practice on pre-professional dance training. (Undergraduate Thesis, East Carolina University). [Online] Available: http://hdl.handle.net/10342/4467 (July 11, 2020)

Miller, A. (2016). The physicality of Spirituality: Art as the Universal Religion. Rutgers University-Camden Graduate School, https://doi.org/doi:10.7282/T3VH5QZ5

Miller, K. (2015). Re-imagining Modern Dance as Transnational Phenomenon Through the Lens of Yoga. [Online] Available: https://escholarship.org/content/qt9bw7b8sv/qt9bw7b8sv.pdf_(September 7, 2020)

Milner, K., Crawford, P., Edgley, A., Hare-Duke L. \& Slade, M. (2020). The experiences of spirituality among adults with mental health difficulties: A qualitative systematic review. Epidemiology and Psychiatric Sciences 29, 34, 1-10. https://doi.org/10.1017/S2045796019000234

Monteiro, N. M., \& Wall, D. (2011). African dance as healing modality throughout the diaspora: The use of ritual and movement to work through trauma. Journal of pan African studies, 4(6), 234-52.

Mukherjee, R. (2016). Karma yoga: A traditional perspective. Yoga Mimamsa, $48(1)$, 37. https://doi.org/10.4103/0044-0507.198708

Murcia, C. Q., Kreutz, G., Clift, S., \& Bongard, S. (2010). Shall we dance? An exploration of the perceived benefits of dancing on well-being, Arts \& Health, 2(2), 149-163. https://doi.org/10.1080/17533010903488582

Nordin-Bates, S. M., Walker, I. J., Baker, J., Garner, J., Hardy, C., Irvine, S., \& Blevins, P. (2011). Injury, imagery, and self-esteem in dance: Healthy minds in injured bodies? Journal of Dance Medicine \& Science, 15(2), 76-85. 
Oliveira, R. (2016). Extemporaneous dance. Redefining Community in Intercultural Context, 5(1), 91-95.

Osbond, C., \& Brown, T. (2016). Dance of awareness: Evolving a 'free-form' approach to exploring early developmental patterns in a group setting. Body, Movement and Dance in Psychotherapy, 11(2-3), 129-143. https://doi.org/10.108o/17432979.2015.1092474

Otto, V. (2014). Yoga for PE: Engaging high school students physically and mentally. Journal of Physical Education, Recreation \& Dance, 85(2), 19-23. https://doi.org/10.1080/07303084.2014.866795

Parsian, N., \& Dunning, T. (2009). Developing and validating a questionnaire to measure spirituality: A psychometric process. Global Journal of Health Science, 1(1), 2-11. doi: 10.5539/gjhs.vinıp2

Payne, H., Warnecke, T., Karkou, V., \& Westland, G. (2016). A comparative analysis of body psychotherapy and dance movement psychotherapy from a European perspective. Body, Movement and Dance in Psychotherapy, 11(2-3), 144-166. https://doi.org/10.1080/17432979.2016.1165291

Ramaswamy, A., \& Deslauriers, D. (2014). Dancer-dance-spirituality: A phenomenological exploration of bharatha natyam and contact improvisation. Dance, Movement \& Spiritualities, 1(1), $105-122$. https://doi.org/10.1386/dmas.1.1.105_1

Roche, J., \& Huddy, A. (2015). Creative adaptations: Integrating Feldenkrais principles in contemporary dance technique to facilitate the transition into tertiary dance education. Theatre, Dance and Performance Training, 6(2), 145-158. https://doi.org/10.1080/19443927.2015.1027452

Sandler, M. \& Lee, J. (2013). Barefoot Walking. Free Your Feet to Minimize Impact, Maximize Efficiency, and Discover the Pleasure of Getting in Touch with the Earth, Three River Press, New York.

Santillano, S. (2006). The Effects of Hatha Yoga on Contemporary Dance: Pitfalls, Practices, and Possibilities. Masters Theses, 7. [Online] Available: https://wesscholar.wesleyan.edu/cgi/viewcontent.cgi?article=1006 \&context=etd_mas_theses (September 8, 2020)

Saoji, A. A., Raghavendra, B., \& Manjunath, N. (2017). Effects of yogic breath regulation: A narrative review of scientific evidence. Journal of Ayurveda and Integrative Medicine, 30, 1e9. [Online] Available: https://www.researchgate.net/profile/Apar_Saoji/publication/322887608_Effects_of_yogic_breath_regulatio n_A_narrative_review_of_scientific_evidence/links/5a742635of7egb2od49o8af9/Effects-of-yogic-breathregulation-A-narrative-review-of-scientific-evidence.pdf (January 10, 2021)

Sengupta, P. (2012). Health impacts of yoga and pranayama: A state-of-the-art review. International Journal of Preventive Medicine, 3(7), 444. https://www.ncbi.nlm.nih.gov/pmc/articles/PMC 3415184/

Siddiqui, S. (2016). Yoga and spirituality, Indian Journal of Health and Wellbeing, 7(12), 1170-1172.

Silfee, V. J., Haughton, C. F., Lemon, S. C., Lora, V., \&. Rosa, M. C. (2017). Spirituality and physical activity and sedentary behaviour among Latino men and women in Massachusetts. Ethnicity \& Disease, 27(1), 3, 3-10. https://doi.org/10.18865/ed.27.1.3

Simpson, S. (2006). Dance Injury Management: DANZ. [Online] Available: https://cdnflightdec.userfirst.co.nz/uploads/sites/danz/files/PDFs/InjuryMgmt.pdf (September 5, 202o)

Snowber, C. (2012). Dance as a way of knowing. New Directions for Adult and Continuing Education, 134, 53-6o. https://doi.org/10.1002/ace.20017

Stewart, I. J. (200o). Sacred Woman, Sacred Dance: Awakening Spirituality Through Movement and Ritual: Simon and Schuster.

Strauss S., Mandelbaum L. (2013) Consuming Yoga, Conserving the Environment: Transcultural Discourses on Sustainable Living. In: Hauser B. (eds) Yoga Traveling. Transcultural Research - Heidelberg Studies on Asia and Europe in a Global Context. Springer, Heidelberg. https://doi.org/10.1007/978-3-319-00315-3_8

Tantia, J. F. (2012). Mindfulness and dance/movement therapy for treating trauma. Mindfulness in the Creative Arts Therapies, 96-107.

Tanyi, R. A. (2002). Towards clarification of the meaning of spirituality. Advanced Nursing, 39 (5), $500-509$.

Tihanyi, B. T., Böőr, P., Emanuelsen, L., \& Köteles, F. (2016). Mediators between yoga practice and psychological well-being: Mindfulness, body awareness and satisfaction with body image. European Journal of Mental Health, 11(1-2), 112.

Thompson, I. A., Wolf, C. P., Mott, E., Baggs, A. S., Eric S. Thompson, E. S., Carmelo Callueng, C., \& Puig, A. (2018). Luna Yoga: A Wellness Program for Female Counselors and Counselors-in-Training to Foster SelfAwareness and Connection, 13(2), 169-184. https://doi.org/10.1080/15401383.2017.1348918

Tsilimigra, K. (1993). The Dance. History-Education-Creativity. Melissa publishing, Athens.

Vaughan, M. (2014). Emanating awareness: Tracing the impact of Bharatanatyam and Iyengar yoga on my contemporary dance and choreographic practice. Dance, Movement \& Spiritualities, 1(1), 87-103. https://doi.org/10.1386/dmas.1.1.87_1 
Victor, C. G. P., \& Treschuk, J. V. (2020). Critical literature review on the definition clarity of the concept of faith, religion, and spirituality. American Holistic Nurses Association, 38, 1, 107-113 https://doi.org/10.1177/o898010119895368

West, J., Otte, C., Geher, K., Johnson, J., \& Mohr, D. C. (2004). Effects of Hatha yoga and African dance on perceived stress, affect, and salivary cortisol. Annals of Behavioral Medicine, 28(2), 114-118. https://doi.org/10.1207/s15324796abm2802_6

Wiese, C., Keil, D., Rasmussen, A. S., \& Olesen, R. (2019). Injury in yoga asana practice: Assessment of the risks, Journal of Bodywork and Movement Therapies, 23(3), 479-488. https://doi.org/10.1016/j.jbmt.2018.o9.151.

Williamson, A. (2016). Reflections on phenomenology, spirituality, dance and movement-based somatics, Journal of Dance \& Somatic Practices, 8(2), 275-301. https://doi.org/10.1386/jdsp.8.2.275_1

Yeung, A., Campbell, B., \& Chan, J. S. (2019). The effects of tai chi and qigong on anxiety and depression. In The Massachusetts General Hospital Guide to Depression (pp. 211-222): Springer. https://link.springer.com/chapter/10.1007/978-3-319-97241-1_16

Zinnbauer, B. J., Pargament, K. I., Cole, B., Rye, M. S., Butter, E. M., Belavich, T. G., \& Kadar, J. L. (1997). Religion and spirituality: Unfuzzying the fuzzy. Journal for the Scientific Study of Religion, 549-564. 